\title{
Erratum to: Detection of Ultrafine Anaphase Bridges
}

\author{
Anna H. Bizard, Christian F. Nielsen, and lan D. Hickson
}

\section{Erratum to:}

Chapter 33 in: Marco Muzi-Falconi and Grant W. Brown (eds.), Genome Instability: Methods and Protocols, Methods in Molecular Biology, vol. 1672, https://doi.org/10.1007/978-1-4939-7306-4_33

The below changes are made in chapter 33:

1. The word "permeabilization" has been replaced with "extraction" throughout the chapter.

2. In 2.2.1: Sigma value has been updated to $25254-9$ from 25,2549

3. In 2.3:

1. Milipore value has been changed to $04-1540$ from 0.14540

2. Abcam value has been changed to ab2179 from ab2175.

4. Life technology value has been changed to Al1011 from Al1001

4. Notes:

29: reference note has been changed to 28 from 26 .

The updated original online version of the chapter can be found at https://doi.org/10.1007/978-1-4939-7306-4_33 